\title{
Trueba Arciniega y otros vs. Paraguay
}

El caso se refiere a la sentencia mediante la cual homologó un acuerdo de solución amistosa entre el Estado mexicano y los representantes de los familiares del señor Mirey Trueba Arciniega. De conformidad con ello se declaró responsable internacionalmente al Estado por la violación de los derechos a la vida e integridad personal en perjuicio de Mirey Trueba Arciniega, por los hechos ocurridos el 22 de agosto de 1998, y por la violación a los derechos a las garantías judiciales, a la protección judicial y a la integridad personal en perjuicio de sus familiares.

\section{Hechos}

En el "Acuerdo de solución amistosa y reconocimiento de responsabilidad del Estado Mexicano en el Caso 12.659. Mirey Trueba Arciniega y Familia" (en adelante "el Acuerdo") las partes acordaron que los hechos que conforman la base fáctica del caso son aquellos determinados por la Comisión Interamericana de Derechos Humanos (en adelante "la Comisión") en su Informe de Fondo N ${ }^{\circ}$ 47/16. En virtud de ello, la Corte se refirió a los hechos narrados por la Comisión en su Informe de Fondo.

La Corte advirtió que se ha incrementado la presencia del ejército en el municipio de Baborigambe, Chihuahua, y que en la década de 1990 el Estado estableció un puesto de mando militar debido a la violencia derivada del narcotráfico. En relación con los hechos ocurridos el 22 de agosto de 1998, el Tribunal constató que Mirey Trueba Arciniega, de 20 años de edad, se encontraba en un vehículo junto con su hermano Vidal Trueba Arciniega y su amigo Jorge Jiménez. El vehículo circulaba por una calle principal en Baborigame cuando un carro militar se acercó y pidió que se detuvieran. De las declaraciones de Jorge Jiménez, quien se encontraba manejando el vehículo, se desprende que cuando detuvo el vehículo el señor Trueba Arciniega se asustó, bajó y corrió por atrás, y un comandante disparó en diez o doce ocasiones. El hermano del señor Trueba 
Arciniega, Vidal Trueba Arciniega, declaró que Mirey Trueba al parecer tuvo miedo de los soldados, y por esta razón habría corrido.

La Corte constató que, conforme a las investigaciones realizadas por las autoridades internas, se determinó que las autoridades militares tenían la intención de revisar la camioneta "Pick Up". Que al detenerse la camioneta bajaron tres civiles y a uno de ellos se le cayó "al parecer un arma" la cual recogió, y con la que caminó apresuradamente para alejarse del lugar al tiempo que expresaba "no me sigan que disparo", por lo que el teniente coronel de infantería Luis Raúl Morales Rodríguez accionó su arma de fuego. De dichas investigaciones se determinó que el militar que disparó nunca tuvo a la vista a Mirey Trueba, por lo que los disparos no se dirigieron a un blanco. Sin embargo, que cuando los militares alcanzaron a al señor Trueba lo encontraron herido de gravedad. El señor Trueba Arciniega fue trasladado a una Clínica del Ejido, y según declaraciones del médico Efrén Royval Simentral, llevaba tres horas sin vida a causa de una herida en la arteria femoral. En el mismo sentido, el Estado indicó que el señor Trueba Arciniega falleció durante su traslado hacia la Clínica.

Respecto a las investigaciones y al procedimiento judicial llevado a cabo a nivel interno, la Corte advirtió que el 22 de agosto de 1998 el señor Tomás Trueba Loera, padre de Mirey Trueba Arciniega, presentó una denuncia ante el Ministerio Público de Baborigame, Chihuahua. El mismo día inició la averiguación previa No. 23/98. El 24 de agosto de 1998 el Ministerio Público Militar resolvió ejercer la acción penal en contra del teniente coronel Luis Raúl Morales Rodríguez como probable responsable del delito de homicidio conforme a los artículos 192 y 193 del Código Penal para el estado de Chihuahua, en relación con el artículo 57 del Código de Justicia Militar. El 30 de agosto de 1998 el Ministerio Público de la jurisdicción ordinaria declinó la competencia del caso y trasladó el expediente al Juez Militar adscrito a la Tercera Región Militar en Mazatlán Sinaloa con fundamento en el artículo 57 del Código de Justicia Militar.

El 22 de febrero de 2000 el Juez militar que conocía la causa, dictó sentencia condenatoria a Luis Raúl Morales Rodríguez por el delito de homicidio simple 
intencional en perjuicio de Mirey Trueba Arciniega, imponiendo una pena de ocho años de prisión ordinaria e inhabilitación para reingresar al Ejército por ocho años. El 19 de enero de 2001 el Supremo Tribunal Militar resolvió el recurso de apelación interpuesto en contra de la sentencia condenatoria y declaró al señor Luis Raúl Morales Rodríguez autor material e involuntario del delito de homicidio culposo por lo que modificó la condena a un año, once meses y quince días de prisión ordinaria. Así, se ordenó la libertad del señor Morales debido a que ya había purgado dicho tiempo en prisión. El 17 de septiembre de 2002 se firmó un convenio entre los representantes de la Secretaría de la Defensa Nacional y José Tomás Trueba Loera en el que se brindó una indemnización por reparación del daño moral y material. La sentencia del Supremo Tribunal Militar de 19 de enero de 2001 quedó en firme.

\section{Homologación del acuerdo de solución amistosa}

La Corte estimó que el reconocimiento realizado por el Estado constituyó una contribución positiva al desarrollo de este proceso y a la vigencia de los principios que inspiran la Convención Americana. Asimismo, consideró que el Acuerdo cumplió con los requisitos materiales y formales en la medida que el mismo ha sido suscripto por las partes en la controversia, las cuales tuvieron la oportunidad de presentar sus observaciones, que el mismo pone fin a la controversia sobre hechos, derechos y reparaciones, y que su contenido es compatible con el objeto y fin de la Convención. En consecuencia homologó el Acuerdo alcanzado por las partes mediante la presente Sentencia. Enseguida, la Corte analizó las medidas de reparación acordadas por las partes, con el fin de determinar su alcance y formas de ejecución, a la luz de los criterios fijados en su jurisprudencia y en relación con la naturaleza, objeto y fin de la obligación de reparar integralmente los daños ocasionados a las víctimas. La Corte recordó que las medidas de reparación acordadas debían ser cumplidas en los términos de la Sentencia, conforme se indicó en la misma. 


\section{Reparaciones}

En relación con las medidas de reparación descritas en el acuerdo de solución amistosa convenido por el Estado y los representantes de las víctimas, la Corte las homologó en los términos descritos en la Sentencia por contribuir a la realización del objeto y fin de la Convención Americana. En ese sentido, la Corte estableció que la sentencia homologatoria constituye por sí misma una forma de reparación. Adicionalmente, ordenó al Estado i) realizar una revisión del caso penal a la luz de las circunstancias y criterios de la época, y tomando en consideración los estándares interamericanos; ii) brindar la atención médica y psicológica que requieran las víctimas, en instituciones de salud especializadas; iii) proporcionar al señor Eleazar Heric Arciniega los recursos para que los destine a generar un proyecto productivo de su elección, entregar los recursos para la compra de una vivienda a la señora Micaela Arciniega Cevallos y para realizar las mejoras necesarias en la casa del señor Tomás Trueba Loera, proporcionar el apoyo alimentario a los padres de Mirey Trueba Arciniega, y realizar un acto público de reconocimiento de responsabilidad; iv) implementar cursos de capacitación a las fuerzas armadas y para los agentes del Ministerio Público de la Federación en los términos descritos en la Sentencia; v) pagar las cantidades fijadas por daño moral, daño inmaterial y lucro cesante; y vi) pagar las cantidades fijadas por concepto de gastos

La Corte Interamericana de Derechos Humanos supervisará el cumplimiento íntegro de la Sentencia, en ejercicio de sus atribuciones y en cumplimiento de sus deberes conforme a la Convención Americana sobre Derechos Humanos, y dará por concluido el caso una vez que el Estado haya dado cabal cumplimiento a lo dispuesto en la Sentencia. 